\title{
Neuroserpin Differentiates Between Forms of Tissue Type Plasminogen Activator via pH Dependent Deacylation
}

\section{OPEN ACCESS}

Edited by:

Francesco Moccia,

University of Pavia, Italy

Reviewed by:

Nigel Peter Birch,

University of Auckland, New Zealand

Tet Woo Lee,

University of Otago, New Zealand

${ }^{*}$ Correspondence:

Bradford S. Schwartz bschwartz@morgridge.org; bschwartz@medicine.wisc.edu

${ }^{\dagger}$ Present address: Karen-Sue B. Carlson, Department of Internal Medicine, Medical College of Wisconsin, Milwaukee, WI, USA Lan Nguyen,

Department of Medicine and Pediatrics, University of Indiana, Indianapolis, IN USA Kat Schwartz,

National Institutes of Health, National Center for Advancing Translational,

Science, Bethesda, MD, USA

¥These authors have contributed equally to this work

Received: 18 November 2015 Accepted: 27 May 2016 Published: 15 June 2016

Citation:

Carlson K-SB, Nguyen L, Schwartz K, Lawrence DA and

Schwartz BS (2016) Neuroserpin Differentiates Between Forms of Tissue Type Plasminogen Activator via $\mathrm{pH}$ Dependent Deacylation. Front. Cell. Neurosci. 10:154. doi: 10.3389/fncel.2016.00154

\author{
Karen-Sue B. Carlson ${ }^{1,2 t \neq}$, Lan Nguyen ${ }^{3 t \neq}$, Kat Schwartz ${ }^{3 t}$, Daniel A. Lawrence ${ }^{4}$ and \\ Bradford S. Schwartz ${ }^{1,3 *}$
}

${ }^{1}$ Department of Biomolecular Chemistry, University of Wisconsin, Madison, WI, USA, ${ }^{2}$ Medical Scientist Training Program, University of Wisconsin, Madison, WI, USA, ${ }^{3}$ Departments of Biochemistry and Medicine, University of Illinois, Urbana, IL, USA, ${ }^{4}$ Departments of Medicine and Molecular and Integrative Physiology, University of Michigan, Ann Arbor, MI, USA

Tissue-type plasminogen activator (t-PA), initially characterized for its critical role in fibrinolysis, also has key functions in both physiologic and pathologic processes in the CNS. Neuroserpin (NSP) is a t-PA specific serine protease inhibitor (serpin) found almost exclusively in the CNS that regulates t-PA's proteolytic activity and protects against t-PA mediated seizure propagation and blood-brain barrier disruption. This report demonstrates that NSP inhibition of t-PA varies profoundly as a function of $\mathrm{pH}$ within the biologically relevant $\mathrm{pH}$ range for the CNS, and reflects the stability, rather than the formation of NSP: t-PA acyl-enzyme complexes. Moreover, NSP differentiates between the zymogen-like single chain form (single chain t-PA, sct-PA) and the mature protease form (two chain t-PA, tct-PA) of t-PA, demonstrating different $\mathrm{pH}$ profiles for protease inhibition, different $\mathrm{pH}$ ranges over which catalytic deacylation occurs, and different $\mathrm{pH}$ dependent profiles of deacylation rates for each form of t-PA. NSP's pH dependent inhibition of t-PA is not accounted for by differential acylation, and is specific for the NSP-t-PA serpin-protease pair. These results demonstrate a novel mechanism for the differential regulation of the two forms of t-PA in the CNS, and suggest a potential specific regulatory role for $\mathrm{CNS}$ pH in controlling t-PA proteolytic activity.

Keywords: neuroserpin, tissue plasminogen activator, serpin, serine protease, decacylation

\section{INTRODUCTION}

Tissue t-PA was initially described as an intravascular protease capable of initiating fibrinolysis by activation of plasminogen to plasmin (Collen, 1980). However, t-PA is also an important extravascular protease in the central nervous system (CNS). T-PA participates in axonal remodeling, neuronal plasticity, long-term potentiation (Seeds et al., 1995), propagation of excitotoxin-induced seizures (Qian et al., 1993; Tsirka et al., 1995; Endo et al., 1999; Wu et al., 2000; Yepes et al., 2002; Pawlak et al., 2005; Fredriksson et al., 2015), progression of cerebral infarct volume during ischemic stroke (Wang et al., 1998; Kano et al., 2000; Yepes et al., 2000), and regulation of blood brain barrier permeability in a number of pathologic conditions

Abbreviations: NSP, neuroserpin; PAI-1, plasminogen activator inhibitor type-1; sct-PA, single chain t-PA; $t$-PA, tissueplasminogen activator; tct-PA, two-chain t-PA; u-PA, urokinase plasminogen activator. 
(Yepes et al., 2003; Su et al., 2008; Fredriksson et al., 2015; Lewandowski et al., 2016). The molecular mechanisms for these physiologic processes include both proteolytic and nonenzymatic t-PA properties.

Similar to other serine proteases, t-PA is synthesized and secreted as a zymogen-like molecule, sct-PA. However, in contrast to other serine protease zymogens, sct-PA exhibits appreciable proteolytic activity, by some measures demonstrating $25 \%$ of the activity of the fully mature protease, two chain t-PA (tct-PA) (Boose et al., 1989; Tachias and Madison, 1997). The primary substrates of t-PA in the CNS are plasminogen and PDGF-CC (Su et al., 2008; Fredriksson et al., 2015). Studies have also suggested that the GluN1 subunit of the NMDA receptor can be cleaved by $\mathrm{t}-\mathrm{PA}$. However, the direct cleavage of the NMDA receptor by t-PA is controversial (Matys and Strickland, 2003; Vivien et al., 2003; Samson et al., 2008; Yuan et al., 2009). It has also been proposed that NMDA receptor mediated excitotoxicity is triggered by sctPA, and not tct-PA (Parcq et al., 2012; Bertrand et al., 2015), identifying a potential proteolytic regulatory mechanism based on the state of the t-PA molecule.

The control of t-PA enzymatic activity is important for regulation of tPA protease-dependent processes. There are two primary inhibitors of t-PA in the CNS, PAI-1 (Colucci et al., 1986) and NSP (Osterwalder et al., 1996; Hastings et al., 1997; Krueger et al., 1997; Osterwalder et al., 1998; Fredriksson et al., 2015). Although the amount of PAI-1 in the CNS is small (Yamamoto et al., 1994; Fredriksson et al., 2015), the molecular chemistry by which it inhibits t-PA enzymatic activity is well characterized and is consistent with the current understanding of serine protease inhibition by a cognate serpin.

Plasminogen activator inhibitor type-1 functions via the established serpin mechanism, which involves presentation of a specific peptide bond within the serpin reactive center loop as a pseudosubstrate for the protease. The protease initiates cleavage as it would with a substrate, forming an acyl-enzyme intermediate with the $\mathrm{P}_{1}$ residue of the serpin (Lawrence et al., 1995; Olson et al., 1995; Wilczynska et al., 1995). However, before the acyl-enzyme can undergo deacylation to complete cleavage of the scissile bond, the serpin undergoes structural rearrangement, translocating the protease, still covalently linked to the $\mathrm{P}_{1}$ residue, $70 \AA$ to the opposite pole of the serpin (Stratikos and Gettins, 1997; Stratikos and Gettins, 1999; Huntington et al., 2000; Dementiev et al., 2006). Within the acyl-enzyme complex, the structure of the protease active site geometry is distorted such that catalytic deacylation can no longer take occur (Huntington et al., 2000; Dementiev et al., 2006). The rearranged acyl-enzyme complex exhibits novel molecular determinants that subsequently mediate specific cellsurface receptor mediated internalization and degradation of the protease-serpin complex (Horn et al., 1998; Stefansson et al., 1998). Hence, protease inhibition by a serpin results in clearance and degradation of both molecules, constituting effectively irreversible inhibition.

Our earlier studies noted a potential mechanistic difference between NSP and PAI-1 inhibition of tPA (Barker-Carlson et al., 2002). In vitro biochemical studies demonstrated only transient inhibition of t-PA by NSP due to increased efficiency of catalytic NSP-t-PA deacylation compared to PAI-1-t-PA acyl-enzyme complexes (Barker-Carlson et al., 2002). The shorter period of stable t-PA inhibition by NSP appears to be biologically meaningful however, as NSP interaction with t-PA in vivo has been identified as a significant negativeregulator of t-PA mediated effects on ischemic stroke (Yepes et al., 2000), seizure propagation (Yepes et al., 2002) and seizure induced blood brain barrier dysregulation (Fredriksson et al., 2015). Interestingly, in both the above noted pathologic states, ischemic stroke and seizure, the $\mathrm{pH}$ of the cerebral spinal fluid decreases to levels that affect the function of human serine proteases (Siesjo, 1985; von Hanwehr et al., 1986).

To determine whether the observed differences in NSP inhibition of t-PA between the in vitro and in vivo systems might reflect an effect of $\mathrm{pH}$ (regulated at 7.2-7.4 in vitro, and decreased to $<6.8$ in vivo) we investigated whether the $\mathrm{pH}$ in which NSP-tPA interactions were studied might be a differentiating factor in these assay systems. The data presented in this paper demonstrate that although NSP mediated inhibition of $\mathrm{t}$-PA is less stable than PAI-1 inhibition of t-PA at physiologically neutral $\mathrm{pH}$, NSP mediated inhibition is modulated by biologically relevant changes in $\mathrm{pH}$, which result in changes in the rate of catalytic deacylation of NSP-t-PA complexes. Moreover, $\mathrm{pH}$ differences also allow NSP to differentiate between sct-PA and tctPA. This leads us to hypothesize that variations in $\mathrm{pH}$ may play a heretofore unrecognized regulatory role in $\mathrm{CNS}$ processes that involve t-PA.

\section{MATERIALS AND METHODS}

\section{Proteins and Reagents}

Tissue-t-PA was purchased from Calbiochem (Leola, CA, USA) and Biopool (Sweden) (>95\%, and >99\% sct-PA, respectively, as assessed by SDS-PAGE under reducing conditions followed by silver staining); tct-PA was generated by treatment of sctPA with plasmin-linked sepharose for a time determined to yield complete conversion of sct-PA to tct-PA as assessed by SDS-PAGE as above (Schwartz and Espana, 1999). Plasmin, spectrozyme t-PA, and traysolol were purchased from American Diagnostica (Greenwich, CT, USA), and two-chain urokinase (tcu-PA) was obtained from Dr. Gene Murano (Monsanto, St. Louis, USA). Cell culture grade bovine serum albumin (BSA) was purchased from Sigma (St. Louis, MO, USA). Recombinant human PAI-1 (14-1b stabilized mutant) was produced in a bacterial expression system as previously described (Berkenpas et al., 1995). Polyclonal rabbit antibody against PAI-1 was a generous gift of Dr. Peter Andreasen (Aarhus University, Denmark) (Zeheb et al., 1987). Polyclonal antibody against NSP was generated in rabbits (Hastings et al., 1997) and HRPconjugated goat antibody against rabbit IgG was purchased from Pierce (Rockford, IL, USA) and Jackson ImmunoResearch Laboratories (West Grove, PA, USA). Human NSP cDNA was obtained from Human Genome Sciences (Rockville, MD, USA) and NSP was expressed in a bacculovirus system (Hastings et al., 1997). 


\section{Electrophoresis and Western Blot Analysis}

Both the mini-protean three apparatus used for electrophoresis and protein transfer, as well as electrophoresis reagents were from BioRad (Hercules, CA, USA). Polyacrylamide gels were cast with $3 \%$ stacking and $10 \%$ separating gels and Western blotting for NSP or PAI-1 was carried out as previously described (BarkerCarlson et al., 2002; Li et al., 2008). Analysis of immunoblots using known amounts of NSP that was intact, cleaved, or in complex with sct-PA demonstrated no detectable difference in epitope detection among the states of NSP (Barker-Carlson et al., 2002). As noted in our previous paper (Barker-Carlson et al., 2002) these reagents were validating as demonstrating no detectable difference in epitope detection among the states of NSP. This information is included in the "Methods" section. A standard curve for NSP-sc-tPA complex detection using this methodology is also included in Supplemental Figures S1A,B. Kodak 1D Software was used to image all films, and Prism 3.0 or 4.0 software were used for data analysis as indicated.

\section{Assessment of Serpin-PA Complex Stability as a Function of $\mathrm{pH}$}

Seventy nanometer NSP, or $140 \mathrm{nM}$ PAI- 1 was incubated at $37^{\circ} \mathrm{C}$ for 5 and $15 \mathrm{~min}$, respectively, with equimolar amounts of the indicated forms of t-PA, or tcu-PA in $0.1 \mathrm{M} \mathrm{NaCl}, 0.001 \mathrm{M}$ sodium phosphate, $\mathrm{pH} 7.2$, and $100 \mu \mathrm{g} / \mathrm{mL}$ BSA. Reactions with NSP included $0.1 \%$ Triton X-100, and those with PAI-1 included $1,000 \mathrm{U} / \mathrm{mL}$ trasylol. Preliminary experiments demonstrated that Triton X-100 had no influence on the function of NSP. Reactions were then diluted fivefold into a series of $0.1 \mathrm{M}$ sodium phosphate buffers at the indicated $\mathrm{pH}$ values, from 6.0 to 8.0, and incubated for $30 \mathrm{~min}$ (NSP) or $90 \mathrm{~min}$ (PAI-1) at $37^{\circ} \mathrm{C}$. Reactions were quenched by addition of SDS-sample buffer, boiled and subjected to SDS-PAGE under reducing conditions, followed by Western blot analysis for NSP or PAI-1. The resulting immunoblot images were analyzed to quantify remaining acylenzyme serpin-protease complexes as a fraction of the complexes at time zero.

\section{Effect of pH on Serpin Inhibition of t-PA Activity}

One hundred and thirty-seven nanometer sct-PA or tct-PA was pre-incubated with $302 \mathrm{nM}$ NSP or $200 \mathrm{nM}$ PAI-1 for 5 (sct$\mathrm{PA}$ ) or $2 \mathrm{~min}$ (tct-PA), at $37^{\circ} \mathrm{C}$ in $0.15 \mathrm{M} \mathrm{NaCl}, 0.001 \mathrm{M}$ Tris, pH 7.2 with $100 \mu \mathrm{g} / \mathrm{mL}$ BSA. Reactions were then diluted fivefold into buffers containing $0.05 \mathrm{M} \mathrm{NaCl}, 0.1 \mathrm{M}$ Tris, $100 \mu \mathrm{g} / \mathrm{mL}$ BSA at the $\mathrm{pH}$ 's indicated, and incubated a further $50 \mathrm{~min}$ (sct-PA) or (tct-PA), or $30 \mathrm{~min}$ at $37^{\circ} \mathrm{C}$. Reactions with NSP contained $0.1 \%$ Triton X-100. Residual t-PA activity was determined by adding spectrozyme t-PA at a final concentration of $1.5 \mathrm{mM}$ using the kinetic analysis module in a Beckman DU640 spectrophotometer. Inhibition of t-PA enzymatic activity was calculated as shown in Equation 1.

Equation 1:

$$
100-100\left(\mathrm{t}-\mathrm{PA}-\operatorname{serpin}_{\mathrm{pHx}} / \mathrm{t}-\mathrm{PA}_{\mathrm{pHx}}\right)=\% \mathrm{t}-\mathrm{PA} \text { inhibition }
$$

Where t-PA-serpin ${ }_{\mathrm{pHx}}$ represents the rate of chromogenic substrate cleavage in reactions containing t-PA and the indicated serpin at a specific $\mathrm{pH}$ between 6.0 and 8.0, and $\mathrm{t}-\mathrm{PA}_{\mathrm{pHx}}$ represents the rate of chromogenic substrate cleavage by t-PA at the same $\mathrm{pH}$ in the absence of serpin.

Neuroserpin-t-PA (either form of t-PA) acyl-enzyme complexes demonstrated no catalytic deacylation at $\mathrm{pH} 6.0$, thus inhibition of t-PA activity at $\mathrm{pH} 6.0$ was designated $100 \%$, and inhibition at other $\mathrm{pH}$ 's was expressed relative to that at $\mathrm{pH} 6.0$, as shown in Equation 2.

Equation 2:

$$
\begin{array}{r}
\% \mathrm{t}-\mathrm{PAinhibition}_{\mathrm{pHx}} / \% \mathrm{t}-\mathrm{PAinhibition}_{\mathrm{pH} 6.0}= \\
\mathrm{t}-\mathrm{PA} \text { inhibition relative to that at } \mathrm{pH} 6.0
\end{array}
$$

Where \% t-PA inhibition $\mathrm{pH}_{\mathrm{x}}$ represents the percent inhibition of t-PA at the indicated $\mathrm{pH}$, and \% t-PA inhibition $\mathrm{pH} 6.0$ is the percent inhibition at $\mathrm{pH} 6.0$, both determined as in Equation 1 . The $\mathrm{pH}$ profile for the relative inhibition of t-PA by NSP was generated and fit to a sigmoidal curve with variable slope non-linear regression using Prism 4.0 software.

\section{Effect of pH on the Rate of NSP-t-PA Acyl-Enzyme Complex Deacylation}

Formation of acyl-enzyme complexes between each form of t-PA and NSP progresses more rapidly than does deacylation (Barker-Carlson et al., 2002). Preliminary experiments defined conditions wherein NSP-t-PA acyl-enzyme complex formation had gone to completion, and therefore the decrement in NSP within those complexes over time could be quantified. Equimolar concentrations $(70 \mathrm{nM})$ of NSP and sct-PA, or tct-PA were incubated for 10 or $2 \mathrm{~min}$, respectively, at $37^{\circ} \mathrm{C}$ in $0.1 \mathrm{M}$ $\mathrm{NaCl}, 0.001 \mathrm{M}$ sodium phosphate, $\mathrm{pH}$ 7.2, with $100 \mu \mathrm{g} / \mathrm{mL}$ BSA and $0.1 \%$ Triton X-100. Reactions were then diluted fivefold (final concentration of t-PA and NSP, $14 \mathrm{mM}$ ) into $0.1 \mathrm{M}$ sodium phosphate buffer, at the indicated $\mathrm{pH}$ between 6.0 and 7.6, containing $100 \mu \mathrm{g} / \mathrm{mL} \mathrm{BSA}$ and $0.1 \%$ Triton X-100, and incubated at $37^{\circ} \mathrm{C}$. At sequential times, aliquots were removed and quenched by addition of SDS-sample buffer, boiled, and analyzed by SDS-PAGE under reducing conditions, followed by Western blot analysis of NSP antigen. The deacylation rate constant at each $\mathrm{pH}$ was determined by fitting the data for the decay of NSP-t-PA acyl-enzyme complexes, which was linear with respect to time at each $\mathrm{pH}$ tested, to the equation for unimolecular decay (Equation 3).

Equation 3:

$$
\ln [\mathrm{NSP}-\mathrm{t}-\mathrm{PA}]_{\mathrm{t}}=\ln [\mathrm{NSP}-\mathrm{t}-\mathrm{PA}]_{\mathrm{o}}-\mathrm{k}_{3} \mathrm{t}
$$

Where $[\mathrm{NSP}-\mathrm{t}-\mathrm{PA}]_{t}$ is the concentration of NSP-t-PA acylenzyme complexes at time $t,[\mathrm{NSP}-\mathrm{t}-\mathrm{PA}]_{0}$ is the initial concentration of complexes, and $\mathrm{k}_{3}$ is the deacylation rate constant (Schechter et al., 1997; Plotnick et al., 2002a,b; Schechter and Plotnick, 2004). 


\section{RESULTS}

Previous work from our labs revealed that the interaction between t-PA and NSP did not form the prototypically stable serpin-protease acyl-enzyme complexes as seen with t-PA and its other cognate serpin, PAI-1. Rather, formation of acyl-enzyme complexes between t-PA and NSP occurred readily, but was followed by rapid deacylation yielding cleaved serpin and active enzyme (Barker-Carlson et al., 2002). In contrast to these unstable in vitro NSP-t-PA complexes, administration of NSP to animals undergoing experimental stroke or seizure yielded evidence of t-PA inhibition (Osterwalder et al., 1998; Yepes et al., 2000, 2002). Unlike in vitro biochemical experiments which are generally performed at $\mathrm{pH} 7.2-7.4$, the CNS is relatively poorly buffered and its $\mathrm{pH}$ drops to as low as 6.0 during pathologies wherein
t-PA plays a role (Meldrum and Brierley, 1973; Meldrum and Horton, 1973; Aminoff and Simon, 1980; Siesjo, 1985, 1986, 1992; von Hanwehr et al., 1986; Bereczki and Csiba, 1993; Meric et al., 1994). We hypothesized that the rapid drop in CNS pH documented to occur following the onset of stroke or seizure might influence the stability of NSP-t-PA acyl-enzyme complexes, and the accompanying inhibition of t-PA enzymatic activity.

To test this hypothesis, NSP was allowed to complex with either sct-PA or tct-PA at $\mathrm{pH} 7.2$, aliquots were then brought to different $\mathrm{pH}$ 's across the range of $6.0-8.0$ and incubated a further $30 \mathrm{~min}$ at $37^{\circ} \mathrm{C}$. The reactions were then analyzed by SDS-PAGE and Western blotting for NSP antigen, and the amount of NSP that remained in complex was compared to the amount initially present in acyl-enzyme complex. Figure 1 demonstrates several findings. First, the effect

A
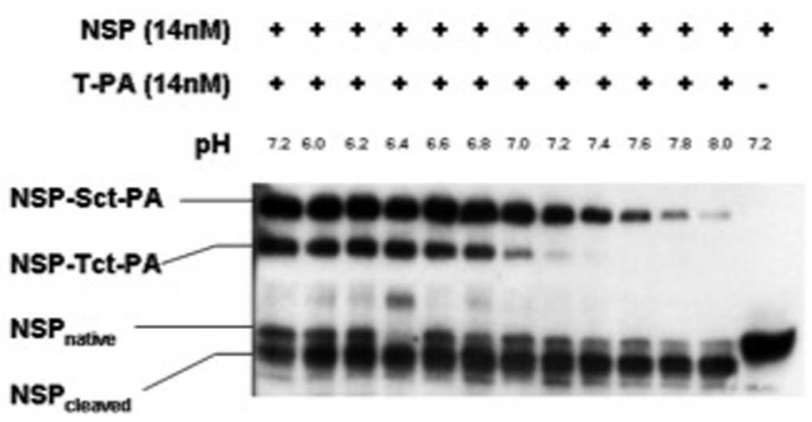

B

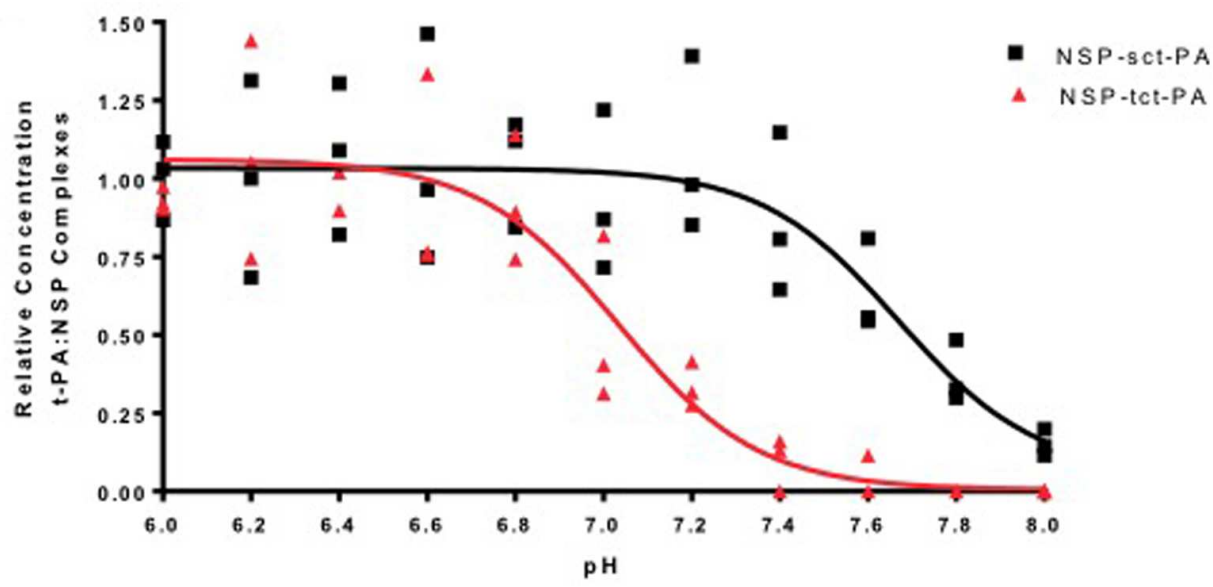

FIGURE 1 | Stability of t-PA-NSP acyl-enzyme complexes is pH dependent. (A) Following initial formation of NSP t-PA complexes with NSP at pH 7.2, reactions were diluted into buffers between 6.0 and 8.0 and incubated at $37^{\circ} \mathrm{C}$ for an additional 30 min as detailed in Methods, then analyzed by SDS-PAGE and Western blotting for NSP. The far left lane illustrates the quantity of NSP-t-PA complexes present at the beginning of the 30-min incubation (maximal complex). The far right lane contains NSP that was not reacted with t-PA. The remaining lanes show the reaction products at the end of the 30 -min incubation at each noted pH. The identities of the individual bands are indicated on the left side of the gel. For ease of comparison, reactions with sct-PA and tct-PA were run in the same wells, since the NSP-t-PA acyl-enzyme complexes involving each form of t-PA are easily resolved. Identical results were obtained when reactions between NSP and each form of NSP were analyzed separately. (B) The ratio of t-PA-NSP complex remaining at the end of the 30-min incubation at the indicated pH, to the amount of complex present immediately before dilution into various $\mathrm{pH}$ buffers was graphed as a function of the $\mathrm{pH}$ into which the reactions were diluted. Triangles: NSP-tct-PA complexes; Squares: NSP-sct-PA complexes. Data are presented as points that represent the individual values, from 3 independent experiments, and lines that represent the means of those values. 
of $\mathrm{pH}$ on acyl-enzyme stability is clearly different for NSP in complex with sct-PA compared to NSP in complex with tctPA. Second, the difference in acyl-enzyme stability between NSP in complex with the two forms of t-PA is greatest at physiologic $\mathrm{pH}, 7.4$. Third, although acyl-enzyme complexes between NSP and tct-PA are unstable at $\mathrm{pH} 7.4$ suggesting tct-PA is free to exert proteolytic activity at physiologic $\mathrm{pH}$, slight acidic shifts result in significant stabilization of these complexes.

The loss of acyl-enzyme complexes does indeed signify catalytic deacylation, as the appearance of cleaved NSP accounts for the reduction in acyl-enzyme-complex with t-PA (Figure 1A), and the $\mathrm{pH}$ range in which this occurs is not compatible with hydroxide mediated deacylation (Calugaru et al., 2001). These findings are consistent with the mechanism for catalytic deacylation of an acyl-enzyme intermediate of a serine proteinase, which requires that the active site histidine within the catalytic triad accept a proton (Plotnick et al., 2002a). At lower $\mathrm{pH}$ values, the histidine is likely already protonated, and thus catalytic deacylation cannot proceed.
These data are also consistent with previous observations that at $\mathrm{pH}$ 7.2, deacylation readily occurs (Barker-Carlson et al., 2002).

These effects do not seem to be general characteristics of t-PA-serpin interactions, as PAI-1-t-PA acyl-enzyme complexes are stable across the $\mathrm{pH}$ range in which NSP-t-PA complexes undergo catalytic deacylation, and no differential stability between PAI-1-sct-PA complexes and PAI-1-tct-PA complexes was evident (Figures 2A,B). In addition, this pattern of acylenzyme instability does not characterize NSP interactions with other proteases closely related to t-PA. Under no circumstances tested were acyl-enzyme complexes between plasmin and NSP detected, but instead NSP acted as a pure plasmin substrate across the $\mathrm{pH}$ range tested (data not shown). Twochain u-PA cleaved NSP with no detectable acyl-enzyme intermediate at physiologic $\mathrm{pH}$, essentially treating the serpin as a substrate. However, rapid adjustment of conditions to very acidic $\mathrm{pH}$ allowed detection of stable tcu-PA-NSP acyl-enzyme complexes (Figure 2C). This is consistent with the pattern observed for non-cognate protease-serpin pairs

\section{A}

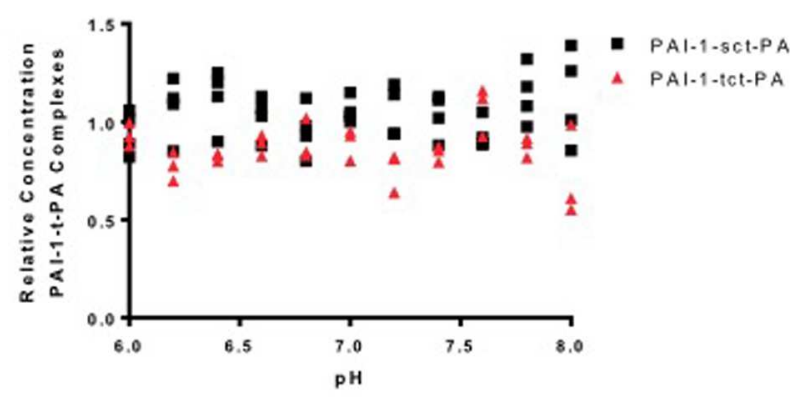

B

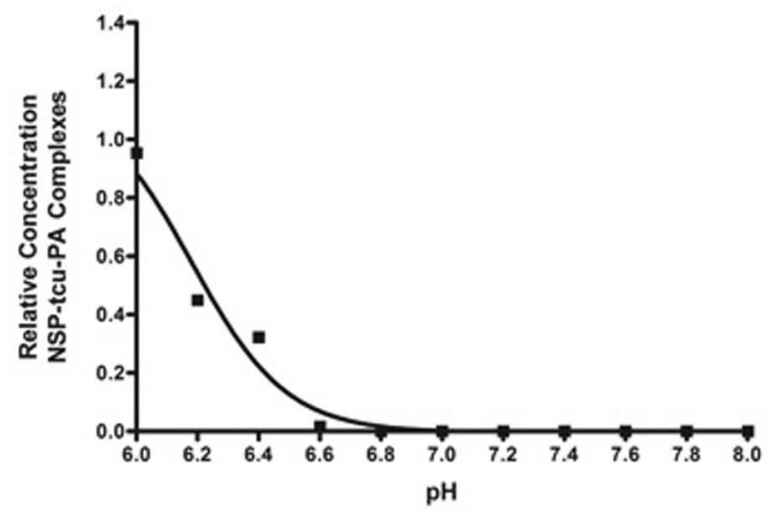

C

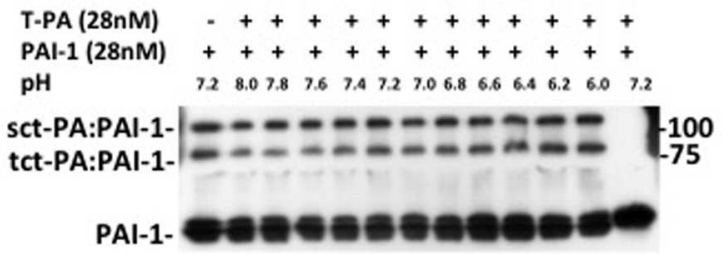

FIGURE 2 | (A,B) pH dependent stability of acyl-enzyme complexes is specific for NSP-t-PA complexes. PAI-1-t-PA complex stability was assayed in a manner analogous to NSP-t-PA complex stability, as described in Methods. The ratio of PAl-1-t-PA complex remaining at the end of the 90-min incubation to the amount of complex present immediately before dilution into various $\mathrm{pH}$ buffers, was graphed as a function of the pH into which the reactions were diluted. Triangles: PAl-1-tct-PA complexes; Squares: PAl-1-sct-PA complexes. Data are presented as points that represent the individual values, from 3 independent experiments Note that incubation of PAl-1-t-PA complexes at various pH's was for $90 \mathrm{~min}$, compared to 30 min for NSP-t-PA complexes, further illustrating the difference in stability between the acyl-enzyme complexes. Panel (B) is a representative western blot from which the data were derived and quantified for (A). (C) tcu-PA and NSP were incubated in buffer $\mathrm{pH} 7.2$ for $1 \mathrm{~min}$ at $37^{\circ} \mathrm{C}$, diluted fivefold into buffers at the indicated $\mathrm{pH}$, and incubated at $37^{\circ} \mathrm{C}$ for $3 \mathrm{~h}$. Samples were then analyzed by SDS-PAGE and western blotting for NSP as described in Methods. The ratio of the concentration of the tcu-PA-NSP complexes remaining after the 3-h incubation at each $\mathrm{pH}$ to the concentration of complex present immediately before dilution into various $\mathrm{pH}$ buffers was graphed against the $\mathrm{pH}$ into which the reactions were diluted. 


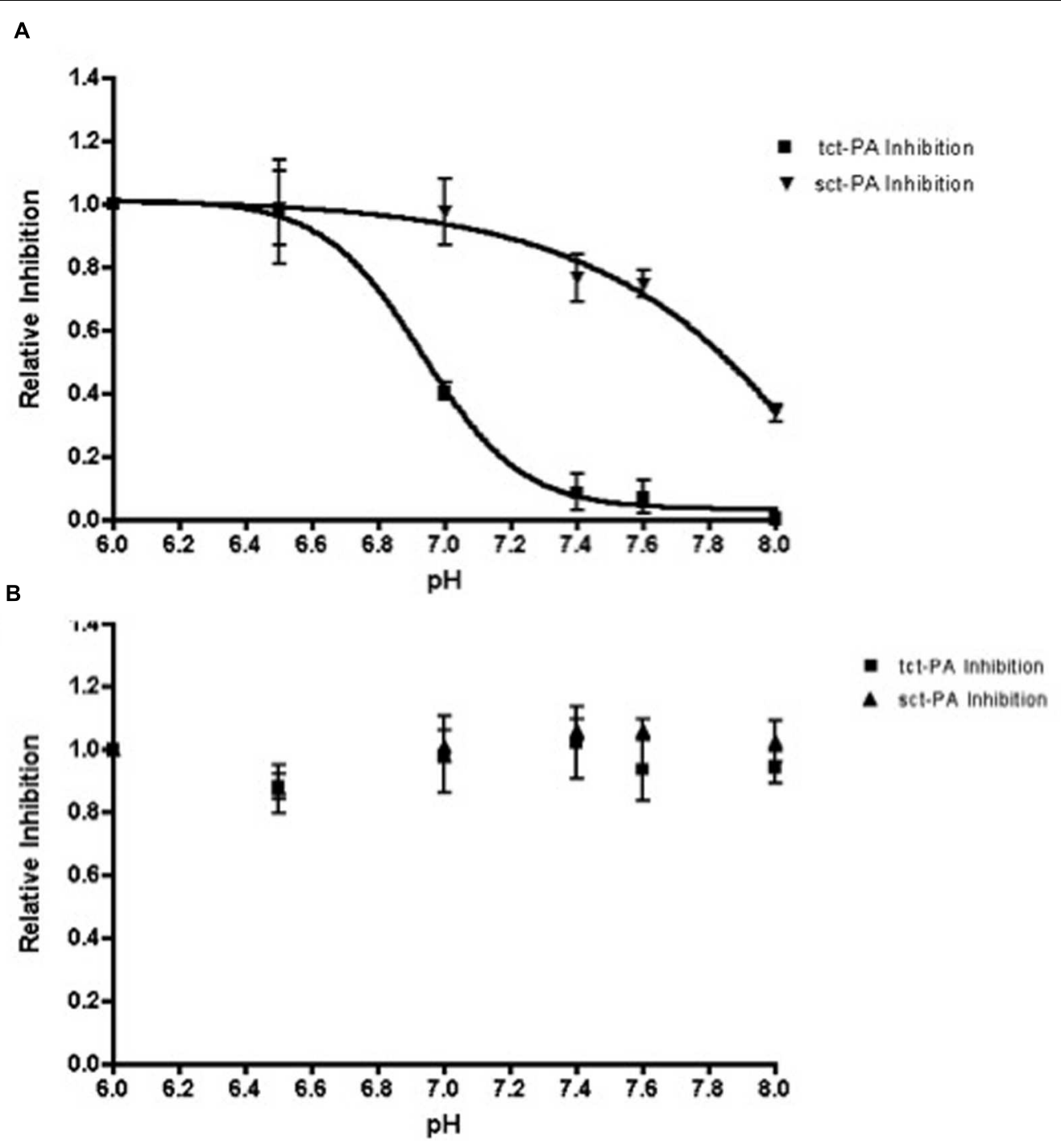

FIGURE 3 | Inhibition of t-PA enzymatic activity by NSP, but not PAI-1, is dependent on pH. Sct-PA or tct-PA were pre-incubated with either (A) NSP, or (B) PAl-1 as detailed in Methods. Reactions were then diluted into buffers with the indicated pH's as in Methods, and the residual t-PA activity determined by quantifying cleavage of a chromogenic substrate. The per cent t-PA inhibition at a given $\mathrm{pH}$ was compared to the maximum inhibition (observed at $\mathrm{pH}$ 6.0) to yield the relative inhibition of each form of t-PA, which is graphed as a function of $\mathrm{pH}$. Triangles: Serpin-sct-PA complexes; Squares: Serpin-tct-PA complexes. Data represent the mean and SEM from 3 independent experiments.

(Schechter et al., 1997; Plotnick et al., 2002a,b; Schechter and Plotnick, 2004). Although single chain u-PA forms acylenzyme complexes with PAI-1 (Manchanda and Schwartz, 1995), no complexes between single chain u-PA and NSP were detected (data not shown). Hence, the regulation of NSP inhibition of $\mathrm{t}-\mathrm{PA}$ over the narrow $\mathrm{pH}$ range known to occur in physiologic and pathologic processes in the mammalian CNS seems selective for this protease-serpin pair. This is in marked contrast to $\mathrm{t}-\mathrm{PA}$ and $\mathrm{u}-\mathrm{PA}$ reacting with the serpin PAI-1, and with the substrate plasminogen (Colucci et al., 1986), and is consistent with the findings of Fredriksson et. al., which suggests that NSP regulates a t-PA mediated process (Fredriksson et al., 2015). The intriguing possibility raised by the present data is that there may be selectivity for regulating the different forms of t-PA under certain biological conditions.

Stability of an acyl-enzyme complex suggests the active site architecture of the protease remains distorted within the complex, preventing catalytic deacylation (Lawrence et al., 1990; Huntington et al., 2000; Dementiev et al., 2006). Therefore, the $\mathrm{pH}$ dependent change in NSP-t-PA acyl-enzyme complex stability should be paralleled by a $\mathrm{pH}$ dependent change in t-PA inhibition. To test this, NSP and both forms of t-PA (sct-PA or tct-PA) were incubated at $\mathrm{pH} 7.2$ to allow acylenzyme complexes to form. The complexes were then diluted into buffers with pH's between 6.0 and 8.0, incubated further, and then added to a t-PA sensitive chromogenic substrate to determine residual t-PA catalytic activity, and thus the degree 
of t-PA inhibition. As seen in Figure 3, t-PA inhibition as a function of $\mathrm{pH}$ closely paralleled the persistence of NSPt-PA acyl-enzyme complexes as a function of $\mathrm{pH}$ (compare Figures $\mathbf{1 B}$ and $\mathbf{3 A}$ ). In addition, the surprising difference in $\mathrm{pH}$ effect on acyl-enzyme complex stability between sct-PA and tct-PA was also seen in $\mathrm{pH}$ dependent inhibition of the two forms of t-PA (Figure 3A). As was seen with acyl-enzyme complex persistence, this pattern of inhibition was unique to the interaction between t-PA and NSP, as PAI-1 showed no difference in t-PA inhibitory efficiency across the $\mathrm{pH}$ range tested, nor did PAI-1 differentiate between the two forms of the enzyme (Figure 3B). These data also suggest that the $\mathrm{pH}$ dependent difference in acyl-enzyme complex persistence was not a function of an SDS-PAGE based assay system, as the experiments determining inhibition of enzymatic activity contained no denaturants.

The above data suggest that NSP may have the capacity to differentially inhibit sct-PA and tct-PA via distinct rates of deacylation of the acyl-enzyme complexes once they are formed. To test this hypothesis, NSP-sct-PA and NSP-tct-PA acylenzyme complexes were pre-formed, transferred to the indicated $\mathrm{pH}$, and rates of acyl-enzyme complex deacylation determined. To ensure the data were not confounded by the formation of new NSP-t-PA acyl-enzyme complexes, measurement of NSP-t-PA complex decay was only performed at times after all NSP had been incorporated into acyl-enzyme complexes, as assessed by SDS-PAGE and western blotting for NSP. Hence, the reduction in NSP-t-PA complex intensity was an accurate measure of deacylation. As seen in Figure 4, the plots of the deacylation rate constants as a function of $\mathrm{pH}$ differed between NSP in complex with sct-PA, and tct-PA. In addition, the rate constants were consistent with the $\mathrm{pH}$ dependent acyl-enzyme persistence and enzyme inhibition with each form of t-PA (Figures 1 and 3). NSP-tct-PA deacylation

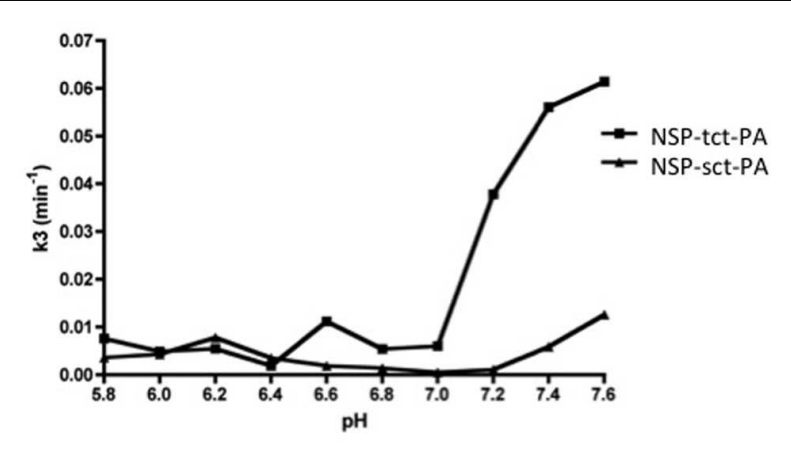

FIGURE 4 | Differential effects of pH on the deacylation rates of NSP-sct-PA and NSP-tct-PA acyl-enzyme complexes. Acyl-enzyme complex formation between sct-PA or tct-PA and NSP was allowed to progress to completion at $\mathrm{pH} 7.2$, as determined in preliminary experiments. Individual reactions were then transferred to the indicated $\mathrm{pH}$ and the decay of acyl-enzyme complexes followed over time by subjecting aliquots to SDS-PAGE and western blotting for NSP antigen as detailed in Methods. The deacylation rate constant $\left(\mathrm{K}_{3}\right)$ was determined for each $\mathrm{pH}$ as described in Methods. Triangles, NSP-sct-PA complexes; Squares, NSP-tct-PA complexes. Data are representative of two independent sets of experiments. rates remained low below $\mathrm{pH}$ 7.0, the range where acylenzyme complexes persisted and tct-PA enzymatic activity was inhibited. As the $\mathrm{pH}$ increased above 7.0, the deacylation rate increased (Figure 4), with parallel decreases in acyl-enzyme complex persistence (Figure 1B) and enzymatic inhibition (Figure 3A). For NSP in complex with sct-PA, the increase in deacylation rate occurred at a significantly higher $\mathrm{pH}, 7.4$, again with corresponding changes in acyl-enzyme complex persistence and enzyme inhibition (Figures $\mathbf{1 B}$ and $\mathbf{3 A}$, respectively).

\section{DISCUSSION}

Given the relatively steep slope of the $\mathrm{pH}$ effect on NSP inhibition of $\mathrm{t}-\mathrm{PA}$, and the similar slopes of $\mathrm{pH}$ dependent stability for acyl-enzyme complexes containing either form of $\mathrm{t}-\mathrm{PA}$ (Figure 1B), it seems that this $\mathrm{pH}$ effect is due to a limited number of residues. The $\mathrm{pH}$ range across which NSP-t-PA catalytic deacylation is regulated is consistent with titration of the catalytic triad histidine (HIS 57, chymotrypsin numbering), and suggests significantly different molecular environments for HIS 57 of sct-PA versus tct-PA in complex with NSP, with a different $\mathrm{H}^{+}$ion concentration required to allow initiation of catalytic deacylation. However, once that threshold has been crossed, the similar titration curves for deacylation of NSP in complex with sct-PA or tct-PA suggests a similar process for each form of t-PA.

It is also possible that the distinct $\mathrm{pH}$ profiles of deacylation signify differences in a non-active site residue on either molecule important for maintaining t-PA in the deformed conformation (i.e., at a contact point between protease and serpin). For instance, it is possible that as a residue at the interface between t-PA and NSP is deprotonated, the ability of NSP to maintain misalignment of t-PA's active site architecture is lost, resulting in recovery of the capacity for catalytic deacylation of the acyl-enzyme complex. If so, the $\mathrm{pH}$ sensitivity of this residue in NSP-sct-PA complexes must differ from that in NSP-tct-PA complexes. Such a scenario would also yield a difference primarily in the threshold at which deacylation is initiated, with subsequent events being similar between forms of t-PA. It will be important to test these and other hypotheses of the molecular mechanism for the differential $\mathrm{pH}$ effects on NSP-t-PA deacylation in future experiments.

This model is consistent with the findings of Calugaru et al. (2001), who observed that in certain non-cognate serpinprotease pairs, $\mathrm{Ca}^{++}$served as an allosteric ligand which restored partial proteolytic capability to the serpin-complexed protease active site, allowing for catalytic deacylation of the serpin-protease intermediate. In the case of NSP-t-PA complexes, there does not appear to be a requirement for an allosteric ligand to bring about a $\mathrm{pH}$ responsive conformation; such a conformation appears to have evolved specifically in NSP-t-PA complexes.

An intriguing correlation may be made with recent findings by Lee et al. (2015), who showed that NSP-t-PA complex 
stability is dependent on evolutionarily conserved residues in NSP, and their findings will inform design of future NSPmutants to identify the amino acid residues that are ultimately responsible for the $\mathrm{pH}$ dependency of NSP-t-PA complex deacylation.

The findings in this report are also consistent with a population of NSP-complexed t-PA molecules that retain some degree of catalytic function in equilibrium with NSP- complexed t-PA molecules exhibiting little or no catalytic function, as hypothesized for unstable serpin-enzyme pairs (Calugaru et al., 2001; Plotnick et al., 2002b). As the somewhat functional t-PA molecules complete the catalytic cleavage of NSP, an essentially irreversible event, the equilibrium model suggests that some molecules in the non-functional conformation then shift to the somewhat functional state, and further catalytic deacylation of complexed NSP occurs. This is depicted in Scheme 1.

Scheme 1:

$$
\mathrm{t}-\mathrm{PA}_{\mathrm{D}}-\mathrm{NSP} \leftrightarrows \mathrm{t}-\mathrm{PA}_{\mathrm{F}}-\mathrm{NSP} \rightarrow \mathrm{t}-\mathrm{PA}+\mathrm{NSP}_{\text {cleaved }}
$$

where $t-P A_{D}$ is deformed and catalytically inactive t-PA in complex with NSP, t-PAF is t-PA that has retained some catalytic function in complex with NSP, and NSP cleaved is NSP that has had the cleavage of $\mathrm{P}_{1}-\mathrm{P}_{1}{ }^{\prime}$ completed. Therefore, the catalytic activity of the $\mathrm{t}-\mathrm{PA}_{\mathrm{F}}$ form of the protease might be $\mathrm{pH}$ sensitive (presumably due to titration of HIS 57), or the stabilization of the t-PA - NSP complex might be $\mathrm{pH}$ dependent (presumably via optimization of intermolecular contacts).

It is interesting that despite the metabolic fragility of the CNS, the CSF has relatively poor buffering capacity. This suggests that allowing changes in $\mathrm{CNS} \mathrm{pH}$ may have been preserved through evolution, a concept that is consistent with $\mathrm{pH}$ having an important regulatory role in the in this anatomic compartment. The data in this paper suggest that specific regulation of t-PA activity by NSP may be an example of a process regulated by shifts in CNS pH. For instance, neuronal depolarization is accompanied by a flux of hydrogen ions at the synapse, and similarly, secretion of NSP-containing dense core secretory vesicles, which have a $\mathrm{pH}$ of 5.0-6.0, would also be expected to transiently lower the local synaptic pH (Loh et al., 1984; Chuang et al., 1999; Parmar et al., 2002; Ishigami et al., 2007). Additional mechanisms of synaptic $\mathrm{pH}$ modulation include the $\mathrm{Ca}+2 / \mathrm{H}+-$ ATPase and carbonic anhydrases that are all functional within the microdomain of the synapse (Sinning and Hubner, 2013). A shift in $\mathrm{pH}$ within a single synapse could be sufficient to modulate NSP inhibitory stability, resultant t-PA activity, and t-PA-dependent neuronal function for that specific synapse (Qian et al., 1993; Seeds et al., 1995; Frey et al., 1996; Calabresi et al., 2000; Zhuo et al., 2000). These same pH alterations can also be hypothesized to modify NMDA receptor activity (Tang et al., 1990; Traynelis and Cull-Candy, 1990; Sinning and Hubner, 2013), with relatively little effect on AMPA- and kainite receptor function (Lei et al., 2001). Although beyond the scope of this manuscript, it is tempting to speculate that the inhibition of NMDA receptor activity noted with decreased extracellular $\mathrm{pH}$ may in part be related to persistence of NSP-t-PA acyl-enzyme complexes, thus altering t-PA interaction with the NR2B subunit of the NMDA receptor (Norris and Strickland, 2007; Parcq et al., 2012).

It is also intriguing to speculate that $\mathrm{pH}$ dependent regulation of t-PA proteolytic activity may be operative in pathologic instances such as seizures, where depolarization goes unchecked. The spread of seizures in mice is t-PA dependent (Yepes et al., 2002), and in a murine model of neonatal febrile seizures, hyperventilation driven alkalinization of the CSF was shown to be the trigger for seizures (Schuchmann et al., 2006). This is consistent with the use of hyperventilation to induce seizures during video EEG monitoring to determine seizure focus in the CNS (Guaranha et al., 2005). Perhaps hyperventilationinduced CNS alkalinization results in loss of NSP inhibitory activity, releasing unopposed t-PA activity, thus facilitating seizure spread.

NSP polymerization has also been shown to be dependent on pH (Belorgey et al., 2010, 2011), and NSP is more resistant to polymerization at low $\mathrm{pH}$ than is PAI-1 (Ishigami et al., 2007; Takehara et al., 2009; Belorgey et al., 2010). Because available NSP or PAI-1 is a function of the balance between polymerized and free serpin, with only free serpin being able to complex with protease, it is possible that the $\mathrm{pH}$ effect described in the present report reflects differences in NSP polymerization, and thus differences in the serpin's availability to inhibit t-PA. However, deacylation was determined starting with NSP that was already in complex with each form of t-PA (Figure 4), something that requires non-polymerized NSP. Hence, the regulatory step described here appears to be separate from the $\mathrm{pH}$ effect on NSP polymerization.

It is also worth considering whether differential $\mathrm{pH}$-dependent regulation of sct-PA and tct-PA reflects different functions for each form of the protease in the CNS. This differentiation may reflect one reason t-PA evolved uniquely as a protease with such a remarkably active zymogen, and is consistent with the distinct role of sct-PA in activating NMDA receptor-dependent neurotoxicity (Parcq et al., 2012; Bertrand et al., 2015) Moreover, Parmar et al.'s finding that tct-PA forms acyl-enzyme complexes with NSP at lower pH than does sct-PA (Parmar et al., 2002) is consistent with different molecular environments in the active sites of the two forms of t-PA during acyl-enzyme formation. Those data, combined with the findings in this paper regarding acyl-enzyme stability, strengthen the hypothesis that changes in $\mathrm{H}+$ ion concentrations are important in regulating the interaction of NSP and t-PA.

Importantly, the properties of NSP that make it uniquely suited as a differential regulator for two forms of t-PA in the $\mathrm{pH}$-sensitive environment of the CNS support the conclusion of Fredriksson et al. (2015) that t-PA is a physiologic target of NSP in the CNS. This is further supported by recent findings that there is very little PAI-1 in neuronal tissue of the normal brain, further supporting the important regulatory function of NSP for t-PA inhibition in the extravascular compartment of the CNS (Yamamoto et al., 1994; Fredriksson et al., 2015).

Further studies will be required to define the molecular mechanisms and physiologic import of this novel form of protease regulation. 


\section{AUTHOR CONTRIBUTIONS}

KS-C and LN contributed equally to this manuscript. KS-C, LN, $\mathrm{KS}, \mathrm{DL}$, and BS designed and implemented the experiments, and co-wrote this manuscript.

\section{FUNDING}

This publication was made possible by National Institutes of Health grants to BS [PHS HL-43506; PHS HL055374] and to DL [PHS HL055374 and NS079639]; and also from the Carle Foundation, Urbana, IL to BS.

\section{REFERENCES}

Aminoff, M. J., and Simon, R. P. (1980). Status epilepticus. Causes, clinical features and consequences in 98 patients. Am. J. Med. 69, 657-666.

Barker-Carlson, K., Lawrence, D. A., and Schwartz, B. S. (2002). Acylenzyme complexes between tissue-type plasminogen activator and neuroserpin are short-lived in vitro. J. Biol. Chem. 277, 46852-46857. doi: 10.1074/jbc.M207740200

Belorgey, D., Hagglof, P., Onda, M., and Lomas, D. A. (2010). pH-dependent stability of neuroserpin is mediated by histidines 119 and 138; implications for the control of beta-sheet A and polymerization. Protein Sci. 19, 220-228. doi: 10.1002/pro.299

Belorgey, D., Irving, J. A., Ekeowa, U. I., Freeke, J., Roussel, B. D., Miranda, E., et al. (2011). Characterisation of serpin polymers in vitro and in vivo. Methods 53, 255-266. doi: 10.1016/j.ymeth.2010.11.008

Bereczki, D., and Csiba, L. (1993). Spatial and temporal changes in tissue $\mathrm{pH}$ and ATP distribution in a new model of reversible focal forebrain ischemia in the rat. Metab. Brain Dis. 8, 125-135. doi: 10.1007/BF00996926

Berkenpas, M. B., Lawrence, D. A., and Ginsburg, D. (1995). Molecular evolution of plasminogen activator inhibitor-1 functional stability. EMBO J. 14, 2969-2977.

Bertrand, T., Lesept, F., Chevilley, A., Lenoir, S., Aimable, M., Briens, A., et al. (2015). Conformations of tissue plasminogen activator (tPA) orchestrate neuronal survival by a crosstalk between EGFR and NMDAR. Cell Death Dis. 6, e1924. doi: 10.1038/cddis.2015.296

Boose, J. A., Kuismanen, E., Gerard, R., Sambrook, J., and Gething, M. J. (1989). The single-chain form of tissue-type plasminogen activator has catalytic activity: studies with a mutant enzyme that lacks the cleavage site. Biochemistry 28, 635-643. doi: 10.1021/bi00428a033

Calabresi, P., Napolitano, M., Centonze, D., Marfia, G. A., Gubellini, P., Teule, M. A., et al. (2000). Tissue plasminogen activator controls multiple forms of synaptic plasticity and memory. Eur. J. Neurosci. 12, 1002-1012. doi: 10.1046/j.1460-9568.2000.00991.x

Calugaru, S. V., Swanson, R., and Olson, S. T. (2001). The pH dependence of serpin-proteinase complex dissociation reveals a mechanism of complex stabilization involving inactive and active conformational states of the proteinase which are perturbable by calcium. J. Biol. Chem. 276, 32446-32455. doi: 10.1074/jbc.M104731200

Chuang, J. Z., Milner, T. A., Zhu, M., and Sung, C. H. (1999). A 29 kDa intracellular chloride channel p64H1 is associated with large dense-core vesicles in rat hippocampal neurons. J. Neurosci. 19, 2919-2928.

Collen, D. (1980). On the regulation and control of fibrinolysis. Edward Kowalski Memorial Lecture. Thromb. Haemost. 43, 77-89.

Colucci, M., Paramo, J. A., and Collen, D. (1986). Inhibition of one-chain and two-chain forms of human tissue-type plasminogen activator by the fast-acting inhibitor of plasminogen activator in vitro and in vivo. J. Lab. Clin. Med. 108, 53-59.

Dementiev, A., Dobo, J., and Gettins, P. G. (2006). Active site distortion is sufficient for proteinase inhibition by serpins: structure of the covalent complex of alpha1-proteinase inhibitor with porcine pancreatic elastase. J. Biol. Chem. 281, 3452-3457. doi: 10.1074/jbc.M510564200

\section{ACKNOWLEDGMENTS}

We thank Debora McCall for her expertise in preparation of the manuscript. The authors would also like to thank Dr. Naveen Manchanda and Sean Li for their discussions of the work detailed in this paper.

\section{SUPPLEMENTARY MATERIAL}

The Supplementary Material for this article can be found online at: http://journal.frontiersin.org/article/10.3389/fncel. 2016.00154

Endo, A., Nagai, N., Urano, T., Takada, Y., Hashimoto, K., and Takada, A. (1999) Proteolysis of neuronal cell adhesion molecule by the tissue plasminogen activator-plasmin system after kainate injection in the mouse hippocampus. Neurosci. Res. 33, 1-8. doi: 10.1016/S0168-0102(98)00105-9

Fredriksson, L., Stevenson, T. K., Su, E. J., Ragsdale, M., Moore, S., Craciun, S., et al. (2015). Identification of a neurovascular signaling pathway regulating seizures in mice. Ann. Clin. Transl. Neurol. 2, 722-738. doi: 10.1002/acn3.209

Frey, U., Muller, M., and Kuhl, D. (1996). A different form of long-lasting potentiation revealed in tissue plasminogen activator mutant mice. J. Neurosci. 16, 2057-2063.

Guaranha, M. S., Garzon, E., Buchpiguel, C. A., Tazima, S., Yacubian, E. M., and Sakamoto, A. C. (2005). Hyperventilation revisited: physiological effects and efficacy on focal seizure activation in the era of video-EEG monitoring. Epilepsia 46, 69-75. doi: 10.1111/j.0013-9580.2005.11104.x

Hastings, G. A., Coleman, T. A., Haudenschild, C. C., Stefansson, S., Smith, E. P., Barthlow, R., et al. (1997). Neuroserpin, a brain-associated inhibitor of tissue plasminogen activator is localized primarily in neurons. Implications for the regulation of motor learning and neuronal survival. J. Biol. Chem. 272, 33062-33067.

Horn, I. R., Van Den Berg, B. M., Moestrup, S. K., Pannekoek, H., and Van Zonneveld, A. J. (1998). Plasminogen activator inhibitor 1 contains a cryptic high affinity receptor binding site that is exposed upon complex formation with tissue-type plasminogen activator. Thromb. Haemost. 80, 822-828.

Huntington, J. A., Read, R. J., and Carrell, R. W. (2000). Structure of a serpinprotease complex shows inhibition by deformation. Nature 407, 923-926. doi: $10.1038 / 35038119$

Ishigami, S., Sandkvist, M., Tsui, F., Moore, E., Coleman, T. A., and Lawrence, D. A. (2007). Identification of a novel targeting sequence for regulated secretion in the serine protease inhibitor neuroserpin. Biochem. J. 402, 25-34. doi: 10.1042/BJ20061170

Kano, T., Katayama, Y., Tejima, E., and Lo, E. H. (2000). Hemorrhagic transformation after fibrinolytic therapy with tissue plasminogen activator in a rat thromboembolic model of stroke. Brain Res. 854, 245-248. doi: 10.1016/S0006-8993(99)02276-3

Krueger, S. R., Ghisu, G. P., Cinelli, P., Gschwend, T. P., Osterwalder, T., Wolfer, D. P., et al. (1997). Expression of neuroserpin, an inhibitor of tissue plasminogen activator, in the developing and adult nervous system of the mouse. J. Neurosci. 17, 8984-8996.

Lawrence, D. A., Ginsburg, D., Day, D. E., Berkenpas, M. B., Verhamme, I. M., Kvassman, J. O., et al. (1995). Serpin-protease complexes are trapped as stable acyl-enzyme intermediates. J. Biol. Chem. 270, 25309-25312. doi: 10.1074/jbc.270.43.25309

Lawrence, D. A., Strandberg, L., Ericson, J., and Ny, T. (1990). Structure-function studies of the SERPIN plasminogen activator inhibitor type 1. Analysis of chimeric strained loop mutants. J. Biol. Chem. 265, 20293-20301.

Lee, T. W., Yang, A. S., Brittain, T., and Birch, N. P. (2015). An analysis approach to identify specific functional sites in orthologous proteins using sequence and structural information: application to neuroserpin reveals regions that differentially regulate inhibitory activity. Proteins 83, 135-152. doi: $10.1002 /$ prot. 24711 
Lei, S., Orser, B. A., Thatcher, G. R., Reynolds, J. N., and Macdonald, J. F. (2001). Positive allosteric modulators of AMPA receptors reduce protoninduced receptor desensitization in rat hippocampal neurons. J. Neurophysiol. 85, 2030-2038.

Lewandowski, S. A., Nilsson, I., Fredriksson, L., Lonnerberg, P., Muhl, L., Zeitelhofer, M., et al. (2016). Presymptomatic activation of the PDGF-CC pathway accelerates onset of ALS neurodegeneration. Acta Neuropathol. 131, 453-464. doi: 10.1007/s00401-015-1520-2

Li, S. H., Gorlatova, N. V., Lawrence, D. A., and Schwartz, B. S. (2008). Structural differences between active forms of plasminogen activator inhibitor type 1 revealed by conformationally sensitive ligands. J. Biol. Chem. 283, 18147-18157. doi: 10.1074/jbc.M709455200

Loh, Y. P., Brownstein, M. J., and Gainer, H. (1984). Proteolysis in neuropeptide processing and other neural functions. Annu. Rev. Neurosci. 7, 189-222. doi: 10.1146/annurev.ne.07.030184.001201

Manchanda, N., and Schwartz, B. S. (1995). Interaction of single-chain urokinase and plasminogen activator inhibitor type 1. J. Biol. Chem. 270, 20032-20035. doi: $10.1074 / j \mathrm{bc} .270 .34 .20032$

Matys, T., and Strickland, S. (2003). Tissue plasminogen activator and NMDA receptor cleavage. Nat. Med. 9, 371-372. doi: 10.1038/nm0403-371 author reply 372-373,

Meldrum, B. S., and Brierley, J. B. (1973). Prolonged epileptic seizures in primates. Ischemic cell change and its relation to ictal physiological events. Arch. Neurol. $28,10-17$.

Meldrum, B. S., and Horton, R. W. (1973). Physiology of status epilepticus in primates. Arch. Neurol. 28, 1-9. doi: 10.1001/archneur.1973.00490190019001

Meric, P., Barrere, B., Peres, M., Gillet, B., Berenger, G., Beloeil, J. C., et al. (1994). Effects of kainate-induced seizures on cerebral metabolism: a combined $1 \mathrm{H}$ and 31P NMR study in rat. Brain Res. 638, 53-60. doi: 10.1016/00068993(94)90632-7

Norris, E. H., and Strickland, S. (2007). Modulation of NR2B-regulated contextual fear in the hippocampus by the tissue plasminogen activator system. Proc. Natl. Acad. Sci. U.S.A. 104, 13473-13478. doi: 10.1073/pnas.0705848104

Olson, S. T., Bock, P. E., Kvassman, J., Shore, J. D., Lawrence, D. A., Ginsburg, D., et al. (1995). Role of the catalytic serine in the interactions of serine proteinases with protein inhibitors of the serpin family. Contribution of a covalent interaction to the binding energy of serpin-proteinase complexes. J. Biol. Chem. 270, 30007-30017.

Osterwalder, T., Cinelli, P., Baici, A., Pennella, A., Krueger, S. R., Schrimpf, S. P., et al. (1998). The axonally secreted serine proteinase inhibitor, neuroserpin, inhibits plasminogen activators and plasmin but not thrombin. J. Biol. Chem. 273, 2312-2321. doi: 10.1074/jbc.273.4.2312

Osterwalder, T., Contartese, J., Stoeckli, E. T., Kuhn, T. B., and Sonderegger, P. (1996). Neuroserpin, an axonally secreted serine protease inhibitor. EMBO J. $15,2944-2953$.

Parcq, J., Bertrand, T., Montagne, A., Baron, A. F., Macrez, R., Billard, J. M., et al. (2012). Unveiling an exceptional zymogen: the single-chain form of tPA is a selective activator of NMDA receptor-dependent signaling and neurotoxicity. Cell Death. Differ. 19, 1983-1991. doi: 10.1038/cdd. 2012.86

Parmar, P. K., Coates, L. C., Pearson, J. F., Hill, R. M., and Birch, N. P. (2002). Neuroserpin regulates neurite outgrowth in nerve growth factor-treated PC12 cells. J. Neurochem. 82, 1406-1415. doi: 10.1046/j.1471-4159.2002.01100.x

Pawlak, R., Melchor, J. P., Matys, T., Skrzypiec, A. E., and Strickland, S. (2005). Ethanol-withdrawal seizures are controlled by tissue plasminogen activator via modulation of NR2B-containing NMDA receptors. Proc. Natl. Acad. Sci. U.S.A. 102, 443-448. doi: 10.1073/pnas.0406454102

Plotnick, M. I., Rubin, H., and Schechter, N. M. (2002a). The effects of reactive site location on the inhibitory properties of the serpin alpha(1)antichymotrypsin. J. Biol. Chem. 277, 29927-29935. doi: 10.1074/jbc.M202 374200

Plotnick, M. I., Samakur, M., Wang, Z. M., Liu, X., Rubin, H., Schechter, N. M., et al. (2002b). Heterogeneity in serpin-protease complexes as demonstrated by differences in the mechanism of complex breakdown. Biochemistry 41, 334-342.

Qian, Z., Gilbert, M. E., Colicos, M. A., Kandel, E. R., and Kuhl, D. (1993). Tissue-plasminogen activator is induced as an immediate-early gene during seizure, kindling and long-term potentiation. Nature 361, 453-457. doi: $10.1038 / 361453 \mathrm{a} 0$
Samson, A. L., Nevin, S. T., Croucher, D., Niego, B., Daniel, P. B., Weiss, T. W., et al. (2008). Tissue-type plasminogen activator requires a co-receptor to enhance NMDA receptor function. J. Neurochem. 107, 1091-1101. doi: 10.1111/j.14714159.2008.05687.x

Schechter, N. M., and Plotnick, M. I. (2004). Measurement of the kinetic parameters mediating protease-serpin inhibition. Methods 32, 159-168. doi: 10.1016/S1046-2023(03)00207-X

Schechter, N. M., Plotnick, M., Selwood, T., Walter, M., and Rubin, H. (1997). Diverse effects of $\mathrm{pH}$ on the inhibition of human chymase by serpins. J. Biol. Chem. 272, 24499-24507. doi: 10.1074/jbc.272.39.24499

Schuchmann, S., Schmitz, D., Rivera, C., Vanhatalo, S., Salmen, B., Mackie, K., et al. (2006). Experimental febrile seizures are precipitated by a hyperthermiainduced respiratory alkalosis. Nat. Med. 12, 817-823. doi: 10.1038/nm1422

Schwartz, B. S., and Espana, F. (1999). Two distinct urokinase-serpin interactions regulate the initiation of cell surface-associated plasminogen activation. J. Biol. Chem. 274, 15278-15283. doi: 10.1074/jbc.274.21.15278

Seeds, N. W., Williams, B. L., and Bickford, P. C. (1995). Tissue plasminogen activator induction in Purkinje neurons after cerebellar motor learning. Science 270, 1992-1994. doi: 10.1126/science.270.5244.1992

Siesjo, B. K. (1985). Acid-base homeostasis in the brain: physiology, chemistry, and neurochemical pathology. Prog. Brain Res. 63, 121-154. doi: 10.1016/S00796123(08)61980-9

Siesjo, B. K. (1986). Calcium and ischemic brain damage. Eur. Neurol. 25(Suppl. 1), 45-56. doi: 10.1159/000116060

Siesjo, B. K. (1992). The ionic basis of neurocytotoxic damage. Clin. Neuropharmacol 15(Suppl. 1), 128A-129A. doi: 10.1097/00002826-19920100100069

Sinning, A., and Hubner, C. A. (2013). Minireview: $\mathrm{pH}$ and synaptic transmission. FEBS Lett. 587, 1923-1928. doi: 10.1016/j.febslet.2013.04.045

Stefansson, S., Muhammad, S., Cheng, X. F., Battey, F. D., Strickland, D. K., and Lawrence, D. A. (1998). Plasminogen activator inhibitor-1 contains a cryptic high affinity binding site for the low density lipoprotein receptor-related protein. J. Biol. Chem. 273, 6358-6366. doi: 10.1074/jbc.273.11.6358

Stratikos, E., and Gettins, P. G. (1997). Major proteinase movement upon stable serpin-proteinase complex formation. Proc. Natl. Acad. Sci. U.S.A. 94, 453-458. doi: 10.1073 /pnas. 94.2 .453

Stratikos, E., and Gettins, P. G. (1999). Formation of the covalent serpin-proteinase complex involves translocation of the proteinase by more than $70 \mathrm{~A}$ and full insertion of the reactive center loop into beta-sheet A. Proc. Natl. Acad. Sci. U.S.A. $96,4808-4813$. doi: $10.1073 /$ pnas. 96.9 .4808

Su, E. J., Fredriksson, L., Geyer, M., Folestad, E., Cale, J., Andrae, J., et al. (2008). Activation of PDGF-CC by tissue plasminogen activator impairs bloodbrain barrier integrity during ischemic stroke. Nat. Med. 14, 731-737. doi: $10.1038 / \mathrm{nm} 1787$

Tachias, K., and Madison, E. L. (1997). Converting tissue type plasminogen activator into a zymogen. Important role of Lys156. J. Biol. Chem. 272, 28-31.

Takehara, S., Onda, M., Zhang, J., Nishiyama, M., Yang, X., Mikami, B., et al. (2009). The 2.1-A crystal structure of native neuroserpin reveals unique structural elements that contribute to conformational instability. J. Mol. Biol. 388, 11-20. doi: 10.1016/j.jmb.2009.03.007

Tang, C. M., Dichter, M., and Morad, M. (1990). Modulation of the N-methylD-aspartate channel by extracellular H+. Proc. Natl. Acad. Sci. U.S.A. 87, 6445-6449. doi: 10.1073/pnas.87.16.6445

Traynelis, S. F., and Cull-Candy, S. G. (1990). Proton inhibition of N-methylD-aspartate receptors in cerebellar neurons. Nature 345, 347-350. doi: $10.1038 / 345347 \mathrm{a} 0$

Tsirka, S. E., Gualandris, A., Amaral, D. G., and Strickland, S. (1995). Excitotoxininduced neuronal degeneration and seizure are mediated by tissue plasminogen activator. Nature 377, 340-344. doi: 10.1038/377340a0

Vivien, D., Fernandez-Monreal, M., Nicole, O., and Buisson, A. (2003). Reply to "Tissue plasminogen activator and NMDA receptor cleavage. Nat. Med. 9, 372-373. doi: 10.1038/nm0403-372

von Hanwehr, R., Smith, M. L., and Siesjo, B. K. (1986). Extra- and intracellular pH during near-complete forebrain ischemia in the rat. J. Neurochem. 46, 331-339. doi: 10.1111/j.1471-4159.1986.tb12973.x

Wang, Y. F., Tsirka, S. E., Strickland, S., Stieg, P. E., Soriano, S. G., and Lipton, S. A. (1998). Tissue plasminogen activator (tPA) increases neuronal damage 
after focal cerebral ischemia in wild-type and tPA-deficient mice. Nat. Med. 4, 228-231. doi: 10.1038/nm0298-228

Wilczynska, M., Fa, M., Ohlsson, P. I., and Ny, T. (1995). The inhibition mechanism of serpins. Evidence that the mobile reactive center loop is cleaved in the native protease-inhibitor complex. J. Biol. Chem. 270, 29652-29655.

Wu, Y. P., Siao, C. J., Lu, W., Sung, T. C., Frohman, M. A., Milev, P., et al. (2000). The tissue plasminogen activator (tPA)/plasmin extracellular proteolytic system regulates seizure-induced hippocampal mossy fiber outgrowth through a proteoglycan substrate. J. Cell Biol. 148, 1295-1304. doi: 10.1083/jcb.148.6.1295

Yamamoto, M., Sawaya, R., Mohanam, S., Loskutoff, D. J., Bruner, J. M., Rao, V. H., et al. (1994). Expression and cellular localization of messenger RNA for plasminogen activator inhibitor type 1 in human astrocytomas in vivo. Cancer Res. 54, 3329-3332.

Yepes, M., Sandkvist, M., Coleman, T. A., Moore, E., Wu, J. Y., Mitola, D., et al. (2002). Regulation of seizure spreading by neuroserpin and tissue-type plasminogen activator is plasminogen-independent. J. Clin. Invest. 109, 15711578. doi: $10.1172 /$ JCI0214308

Yepes, M., Sandkvist, M., Moore, E. G., Bugge, T. H., Strickland, D. K., and Lawrence, D. A. (2003). Tissue-type plasminogen activator induces opening of the blood-brain barrier via the LDL receptor-related protein. J. Clin. Invest. 112, 1533-1540. doi: 10.1172/JCI200319212

Yepes, M., Sandkvist, M., Wong, M. K., Coleman, T. A., Smith, E., Cohan, S. L., et al. (2000). Neuroserpin reduces cerebral infarct volume and protects neurons from ischemia-induced apoptosis. Blood 96, 569-576.
Yuan, H., Vance, K. M., Junge, C. E., Geballe, M. T., Snyder, J. P., Hepler, J. R., et al. (2009). The serine protease plasmin cleaves the amino-terminal domain of the NR2A subunit to relieve zinc inhibition of the N-methyl-Daspartate receptors. J. Biol. Chem. 284, 12862-12873. doi: 10.1074/jbc.M8051 23200

Zeheb, R., Rafferty, U. M., Rodriguez, M. A., Andreasen, P., and Gelehrter, T. D. (1987). Immunoaffinity purification of HTC rat hepatoma cell plasminogen activator-inhibitor-1. Thromb. Haemost. 58, 1017-1023.

Zhuo, M., Holtzman, D. M., Li, Y., Osaka, H., Demaro, J., Jacquin, M., et al. (2000). Role of tissue plasminogen activator receptor LRP in hippocampal long-term potentiation. J. Neurosci. 20, 542-549.

Conflict of Interest Statement: The authors declare that the research was conducted in the absence of any commercial or financial relationships that could be construed as a potential conflict of interest.

Copyright (c) 2016 Carlson, Nguyen, Schwartz, Lawrence and Schwartz. This is an open-access article distributed under the terms of the Creative Commons Attribution License (CC BY). The use, distribution or reproduction in other forums is permitted, provided the original author(s) or licensor are credited and that the original publication in this journal is cited, in accordance with accepted academic practice. No use, distribution or reproduction is permitted which does not comply with these terms. 